\title{
Bioactivity evaluation of organic solvent extractions of Ganoderma lucidum: a Sri Lankan basidiomycete
}

\author{
Kalpa W. Samarakoon ${ }^{1,3}$, Ji-Hyeok Lee ${ }^{3}$, E. Dilip De Silva ${ }^{1}$, Eun-A Kim ${ }^{3}$, Ravi L.C. Wijesundara ${ }^{2}$, \\ H.H. Chaminda Lakmal ${ }^{1,3}$ and You-Jin Jeon ${ }^{3 *}$ \\ ${ }^{1}$ Department of Chemistry, Faculty of Science, University of Colombo, Colombo 03. \\ ${ }^{2}$ Department of Plant Sciences, Faculty of Science, University of Colombo, Colombo 03. \\ ${ }^{3}$ Department of Marine Life Science, School of Marine Biomedical Sciences, Jeju National University, Jeju 690-756, Republic of Korea.
}

Revised: 12 April 2013; Accepted: 09 May 2013

\begin{abstract}
In this study, bioactivities of organic solvent extracts derived from nine species of terrestrial fungi were evaluated. The methanol extract of Ganoderma lucidum was selected as a potent sample with antibacterial activity showing growth inhibitory effects against pathogenic bacterial strains. Solvent-solvent partition chromatography was used to seperate four fractions from the G. lucidum crude sample. Among the fractions, chloroform fraction was proved to comprise seven major compounds in HPLC analysis. The positive peak 4, at $27.0 \mathrm{~min}$ retention time on the UV detector at 290 and $365 \mathrm{~nm}$, which corresponded to the negative peak at $680 \mathrm{~nm}$ on-line HPLC-ABTS $^{+}$chromatogram was identified as an antioxidant compound. Antioxidant activity against 2,2-diphenyl-1picrylhydrazyl (DPPH) was tested using radical scavenging activity with the electron spin resonance spectrometer (ESR). The highest activity was shown by the chloroform fraction with a $\mathrm{IC}_{50}$ value $0.684 \pm 0.31 \mathrm{mg} \mathrm{mL}^{-1}$. The inhibitory effect of nitric oxide (NO) production (\%) was reported as the highest with the $\mathrm{IC}_{50}$ value $30.38 \pm 0.03 \mu \mathrm{g} \mathrm{mL}-1$ from chloroform fraction against lipopolysaccharide (LPS) induced RAW 264.7 cells in vitro. The methanol and ethyl acetate fractions also showed similar but lesser effects with $\mathrm{IC}_{50}$ values $33.09 \pm 0.04$ and $122.9 \pm 0.82 \mu \mathrm{g} \mathrm{mL}^{-1}$, respectively. Cell viability (\%) by the MTT assay confirmed that there was no cytotoxic effect when treated with G. lucidum extracts at all concentrations. These results demonstrate the potential of using chloroform extracts of G. lucidum in antibacterial, antioxidant and antiinflammatory therapeutic applications.
\end{abstract}

Keywords: Antibacterial activity, anti-inflammatory effect, antioxidant effect, Ganoderma lucidum, on-line HPLC-ABTS ${ }^{+}$, terrestrial fungi.

\section{INTRODUCTION}

Fungi are the major decomposers in certain ecosystems and essential associates of many organisms. Highthroughput sequencing has estimated that there are more than 5.1 million fungal species in different habitats including soil, water and organisms (Blackwell, 2011). They are rich sources of secondary metabolites. Large numbers of fungal species are still chemically unexplored and conceived as promising sources of primary compounds for drug discovery and developments. The phylum basidiomycetes is one of the largest group of fungi among the four groups of true fungi; zygomycetes, basidiomycetes, ascomycetes, and deuteromycetes (Guarro et al., 1999). Polypores are a large group of terrestrial fungi of the phylum basidiomycetes and a major source of pharmacologically active substances (Zjawiony, 2004).

The biochemical evaluation of terrestrial fungi has resulted in the isolation of a large number of secondary metabolites. Most of them are species specific and biosynthesized from a relatively small number of key intermediates, namely acetate, mevalonate, shikimate and amino acids. These metabolites are categorized based on their biosynthesis into groups such as terpenoids, polyketides, shikimates and alkaloids, and have shown pharmacological and medicinal value for the cure or alleviation of disease symptoms of humans. Therefore, 
mining of new bioactive secondary metabolites from terrestrial fungi is considered as an interesting aspect by many researchers recently.

Sri Lanka is a biodiversity hotspot comprising a high portion of endemic species among the fauna and flora: approximately $25 \%$ of the flowering plants and $16 \%$ of the mammals in the island are endemic. However, endemism among the 1920 fungal species of Sri Lanka is unknown. The earliest record of Sri Lankan fungi goes back to 1783; two species are recorded under the names Peziza ceylonsche and Peziza limbosa in "The Fungi of Ceylon" by Petch and Bisby (1950). Another publication by Coomaraswamy, (1979) gives a detailed account of the research carried out on Sri Lankan fungi and lists 2180 species belonging to 106 genera. Ganoderma lucidam and Ganoderma applantum have been identified as the most common ceylon polypori occurring all over the island.

Only a limited number of chemical and biological studies have been done on Sri Lankan fungi. In a study to investigate the antibiotic activities of Sri Lankan fungi, 21 basdiomycetes species have been screened against bacterial strains including Staphylococcus aureus, Streptococcus sp., Psuedomonas aeruginosa, Escherichia coli and Klebsiella sp. Volvariella volvacea has been identified as a promising fungal species and led to the isolation of ergosterol peroxide (Perera et al., 2001). In addition, two new lanostane triterpenoids along with three known lanostanoids with anticancer activities have been isolated from Ganoderma applantam (polyporaceae) (De silva et al., 2006).

This study attempted to identify the prominent bioactive metabolites from randomly selected Sri Lankan terrestrial fungal species followed by the screening of their antibacterial activities. Antioxidant and antiinflammatory potentials of organic solvent extracts of the prominent fungal species were determined using advanced chromatographic methods to evaluate their efficacy to isolate novel natural products.

\section{METHODS AND MATERIALS}

\section{Chemicals and reagents}

2,2-diphenyl-1-picrylhydrazyl (DPPH) and 2,2'-azinobis (3-ethylbenzothiazoline-6-sulfonic acid) (ABTS) were purchased from Sigma Chemicals Co. (St. Louis, USA). Nutrient agar (NA) and potato dextrose agar (PDA) were purchased from Difco (Sparks, MD, USA). All the chemicals and solvents used were of analytical grade.

\section{Fungi sample collection and extraction}

Fresh samples of nine fungal species were collected based on the different morphological features of the fruiting bodies, from the Western Province of Sri Lanka during July and October 2007 and identified. Voucher specimens were deposited in the herbarium of the Department of Plant Science, University of Colombo, Sri Lanka. Freshly collected fruiting bodies of the fungal species were washed well and dried at room temperature for $24 \mathrm{~h}$. The fruiting bodies were cut into small pieces and stored at $-20{ }^{\circ} \mathrm{C}$. These fungal samples were lyophilized and ground into fine powder. A $5 \mathrm{~g}$ quantity of each sample was mixed with $100 \%$ methanol and kept in a shaking incubator at $25{ }^{\circ} \mathrm{C}$ for 1 day and filtered under a vacuum using a Whatman no.1 (Whatman Ltd., Maidenstone, England) filter paper. The methanol was evaporated in a rotary evaporator (Fisher Scientific, Loughborough, UK) and each of the sample was prepared into a $20 \mathrm{mg} \mathrm{mL}^{-1}$ concentration.

\section{Disk diffusion assay}

The methanol extracts from the terrestrial fungal species were screened for antibacterial activity using agar diffusion technique against 4 bacterial strains (Rota et al., 2004). The selected bacterial strains, Bacillus subtilis, Staphylococcus oureus, Escherichia coli and Klebsiella aerogenes were grown in nutrient agar. Sterilized filter paper disks (Whatman no. 1, $6 \mathrm{~mm}$ diameter) containing $50 \mu \mathrm{L}(1 \mathrm{mg})$ of each extract was applied to the surface of the agar plates that were previously seeded with bacterial strains by spreading $0.1 \mathrm{~mL}$ of overnight culture. Methanol was used as a negative control. The plates were incubated overnight at respective temperatures, and the diameter of the growth inhibition zone was measured to the nearest millimeter. The scale of the measurement was as follows: $>9 \mathrm{~mm}$ clear zone as the strong inhibitory activity; 9-4 $\mathrm{mm}$ clear zone as the moderate/mild inhibitory activity; and $<4 \mathrm{~mm}$ as the low inhibitory activity, excluding the diameter of the filter paper disks (6 mm).

\section{On-line-HPLC analysis of Ganoderma lucidum extracts}

Solvent-solvent partition chromatography was used to separate four different solvent extracts from G. lucidum. High-performance liquid chromatography (HPLC) system used in this experiment consisted of binary Waters 515 pump, Waters 2489 UV/Vis and 2998 photodiode array (PDA) detector and Waters 2707 auto sampler with the interface $\mathrm{ABTS}^{+}$radical analyser (Waters, Milford, MA 01757 , USA). $10 \mu \mathrm{L}$ of the $5 \mathrm{mg} \mathrm{mL}^{-1}$ concentration 
sample was run at $0.2 \mathrm{~mL} \mathrm{~min}^{-1}$ flow rate on Atlantis T3 $3 \mu \mathrm{M} 3.0 \times 150 \mathrm{~mm}$ column (Waters, USA) using a gradient of acetonitrile $(\mathrm{ACN}) \sim$ water slovent system (0 $40 \mathrm{~min}: 10: 100 \mathrm{v} / \mathrm{v}, 40 \sim 50 \mathrm{~min}: 100 \% \mathrm{v} / \mathrm{v})$ and the absorbance detected at 290 and $365 \mathrm{~nm}$. For the preparation of 2,2'-azinobis(3-ethylbenzothiazoline-6sulfonic acid) (ABTS) radical solution, $2 \mathrm{mM}$ ABTS radical stock solution containg $2.5 \mathrm{mM}$ potassiun persulfate in water was diluted 30-fold using HPLC grade water. This solution was incubated overnight in dark at room temperature for radical stabilization. The separated analytes were sent to ' $\mathrm{T}$ ' piece and reacted post-column with the ABTS radical in a reaction coil at $40{ }^{\circ} \mathrm{C}$. The reduction was detected as a negative peak by UV detector set at $680 \mathrm{~nm}$.

\section{DPPH radical scavenging assay}

2,2-diphenyl-1-picrylhydrazyl (DPPH) is a free radical donor, which can be detected via electron spin resonance (ESR) spectrometry (JES-FA machine, JOEL, Japan) by the technique described by Nanjo et al. (1996). $60 \mu \mathrm{L}$ of each sample was added into $60 \mu \mathrm{L}$ of DPPH $\left(60 \mu \mathrm{mol} \mathrm{L}^{-1}\right)$ in ethanol. After 10s of vigorous mixing, the solutions were transferred into $100 \mu \mathrm{L}$ Teflon capillary tubes and fitted into the cavity of the ESR spectrometer. The spin adduct was determined on an ESR spectrometer exactly $2 \mathrm{~min}$ later. The measurement conditions were as follows: central field $3475 \mathrm{G}$, modulation frequency $100 \mathrm{kHz}$, modulation amplitude $2 \mathrm{G}$, microwave power $5 \mathrm{~mW}$, gain $6.3 \times 10^{5}$, temperature $298 \mathrm{~K}$.

\section{Cell culture}

The murine macrophage cell line RAW 264.7 was purchased from the Korean Cell Line Bank (KCLB, Seoul, Korea) and cultured in Dulbecco's modified eagle medium (DMEM) supplemented with $100 \mathrm{U} \mathrm{mL}^{-1}$ of penicillin, $100 \mu \mathrm{g} \mathrm{mL}^{-1}$ of streptomycin and $10 \%$ fetal bovine serum (FBS). The cells were incubated and maintained in an atmosphere of $5 \% \mathrm{CO}_{2}$ at $37{ }^{\circ} \mathrm{C}$ and sub cultured every $2 \mathrm{~d}$. Exponential phase cells were used throughout the experiments.

\section{Determination of nitric oxide (NO) production}

RAW 264.7 cells $\left(1 \times 10^{5}\right.$ cell $\left.\mathrm{mL}^{-1}\right)$ were placed in a 24-well plate and after $24 \mathrm{~h}$, the cells were pre-incubated with various concentrations of the sample at $37^{\circ} \mathrm{C}$ for $1 \mathrm{~h}$. Further incubation was done for another $24 \mathrm{~h}$ with LPS $\left(1 \mu \mathrm{g} \mathrm{mL}^{-1}\right)$ at the same temperature. After the incubation, the quantity of nitrite accumulated in the culture medium was measured as an indicator of NO production (Lee et al., 2007). Briefly, $100 \mu \mathrm{L}$ of the cell culture medium was mixed with $100 \mu \mathrm{L}$ of Griess reagent ( $1 \%$ sulfanilamide and $0.1 \%$ naphthylethylenediamine dihydrochloride in $2.5 \%$ phosphoric acid), incubated at room temperature for $10 \mathrm{~min}$, and the optical density at $540 \mathrm{~nm}$ was measured using an enzyme-linked immunosorbent assay (ELISA) microplate reader (Sunrise, Tecan Co. Ltd., Australia). The fresh culture medium was used as a blank in every experiment.

\section{Cytotoxicity assessment using MTT assay}

The cytotoxicity of $G$. lucidum extracts against RAW 264.7 cell was determined using a colorimetric MTT assay. Cells were seeded in a 24 -well plate at a concentration of $1 \times 10^{5}$ cells $\mathrm{mL}^{-1} .24$ hours after seeding, the cells were treated with extracts and incubated for an additional $24 \mathrm{~h}$ at $37^{\circ} \mathrm{C}$. MTT stock solution $\left(50 \mu \mathrm{L} ; 2 \mathrm{mg} \mathrm{mL}^{-1}\right.$ in PBS) was added to each well to a total reaction volume of $250 \mu \mathrm{L}$. After $3 \mathrm{~h}$ of incubation, the supernatants were aspirated. The formazan crystals in each well were dissolved in $200 \mu \mathrm{L}$ of dimethylsulfoxide (DMSO), and the absorbance was measured with an ELISA plate reader at $540 \mathrm{~nm}$.

\section{Statistical analysis}

All the data were expressed as mean \pm standard deviation of three determinations. Statistical comparison was performed via a one-way analysis of variance followed by Duncan's multiple range test (DMRT). P values of less than $0.05(p<0.05)$ were considered as significant.

\section{RESULTS}

\section{Antibacterial activity}

The methanol extracts of nine randomly selected fungi were used to determine the growth inhibitory activity using the disc diffusion assay against four pathogenic bacterial strains including 2 Gram negative (Escherichia coli and Klebsiella aerogenes) and 2 Gram positve (Bacillus subtilis and Staphylococcus aureus) bacterial strains, respectively. The diameter of the growth inhibition zone (excluding the diameter of the filter paper disc $-6 \mathrm{~mm}$ ) of pathogenic bacteria from the methanolic extracts of fungi are presented in Figure 1. Eight of the nine crude fungal extracts exhibited growth inhibition zones in at least one of the bacterial strains tested. Crude extracts of(FS3); Daldinia cocentrica, (FS5); Ganoderma lucidum, (FS6); Pycnopoius cinnbarinus and (FS9) Xylaria polymorpha showed a significantly high growth inhibition against all four pathogenic bacterial strains. Only the crude extract of Trametes suaveolens (FS8) showed no growth inhibition against all the pathogenic 
bacterial strains. Among the growth inhibitory activity of crude extracts, G. lucidum showed the highest and promising antibacterial activity against all the Gram positive and negative bacteria strains and was selected for further bioassays using different polar fractions after extraction from different organic solvents.



Figure 1: Diameter of the growth inhibition zone (excluded disk diameter of $6 \mathrm{~mm}$ ) against the four pathogenic bacterial strains (Bacillus subtilis, Staphylococcus aureus, Escherichia coli and Klebsiella aerogenes) from the methanol extracts of the fungi species. The concentration of the fungi extract was used as $1 \mathrm{mg} /$ disc.

${ }^{a}$ All data are means of three determinations

FS1: Auricularia auricula judae; FS2: Agaric impudicus; FS3: Daldinia cocentrica; FS4: Ganoderma sp.; FS5: Ganoderma lucidum; FS6: Pycnopoius cinnbarinus;

FS7: Schizophyllum commune; FS8: Trametes suaveolens; FS9: Xylaria polymorpha

\section{Ganoderma lucidum extracts and on-line-HPLC} profiles

The extracts of fruiting body of G. lucidum using (1:1) methanol:chloroform solvent system was obtained and

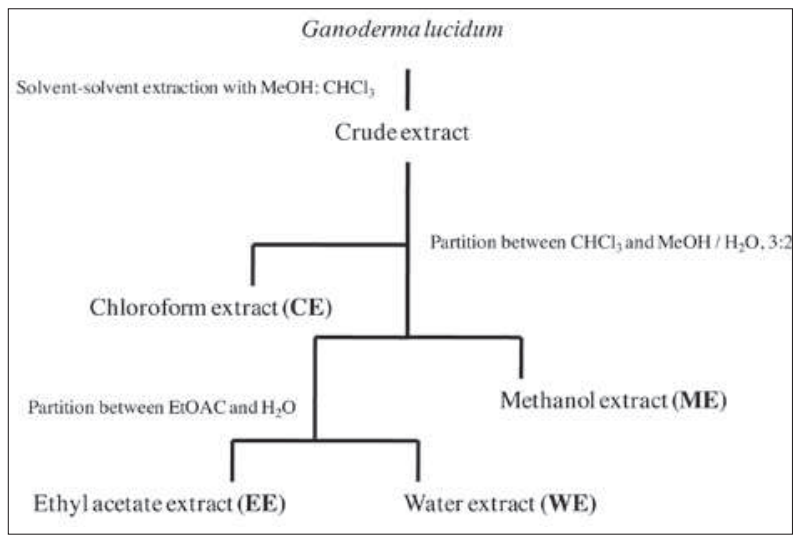

Figure 2: Extraction approaches of Ganoderma lucidum fungi sample using different organic solvents partitioned into different fractions according to the polarity of organic solvents used. The solvent-solvent partition chromatography approach (Figure 2) was used to fractionate the G. lucidum crude sample into four different fractions with varying polarity.

Thus, methanol, chloroform, ethyl acetate and water fractions were used to analyze the on-line-HPLC profiles. Many compounds were found in the chloroform fraction only. Figure 3 (A) and (B) depict the chromatographic profile of the chloroform fraction of G. lucidum in the HPLC condition of a gradient of acetonitrile $(\mathrm{ACN})$ : water slovent system at flow rate $0.2 \mathrm{~mL} \min ^{-1}(0 \sim 40$ min: 10:100 v/v, $40 \sim 50 \mathrm{~min}: 100 \% v / v)$ and absorption monitored at 290 and $365 \mathrm{~nm}$, respectively. Seven major peaks were investigated in this study for chemical identification and only one peak (4) was determined to be of antioxidant value with the $\mathrm{ABTS}^{+}$radical scavenging effects. Figure $3(\mathrm{C})$ depicts the $\mathrm{ABTS}^{+}$radical recorded at $680 \mathrm{~nm}$ as negative peak system. The positive peak (4) on the UV detector at 290 and $365 \mathrm{~nm}$ in on-line HPLC corresponded to the negative peak at $680 \mathrm{~nm}$ $\mathrm{ABTS}^{+}$radical chromatogram. The negative peak area 
is dependent on the amount of antioxidant activity of the compound. The chloroform fraction gave positive evidence on the $\mathrm{ABTS}^{+}$radical scavenging activity and was considered as a fraction with potential for further purifications.

\section{Antioxidant activity}

The scavenging activity of three different organic solvent extracts including methanol (ME), chloroform (CE) and ethyl acetate (EE) fractions of G. lucidum were measured

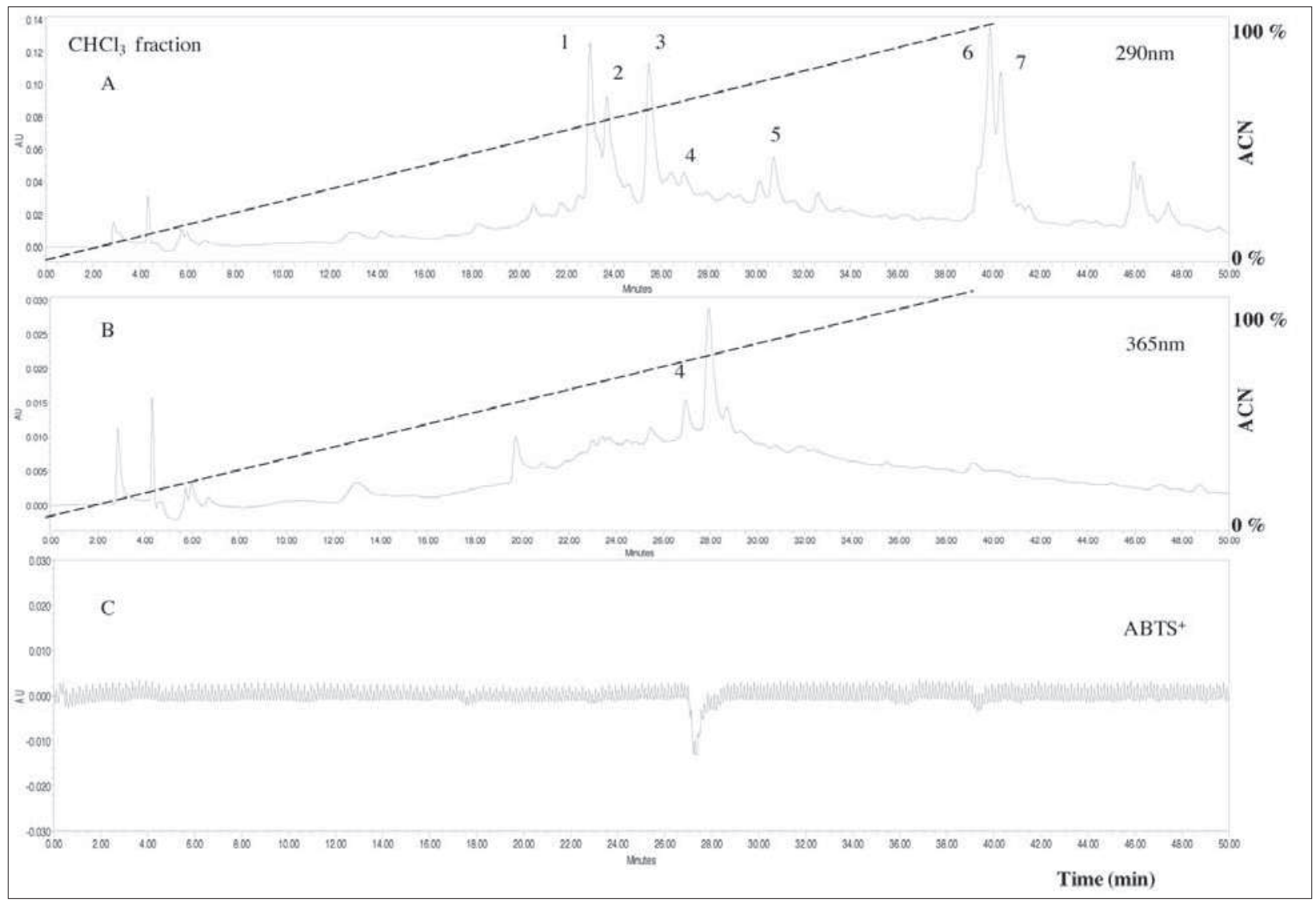

Figure 3: On-line HPLC chromatogram of the chloroform fraction from Ganoderma lucidum. (A) HPLC chromatogram of chloroform extract of G. lucidum at $290 \mathrm{~nm}$ and identified main compounds (1 - 7 peaks). (B) HPLC chromatogram of chloroform extracts of G. lucidum at $365 \mathrm{~nm}$ and identified antioxidative compound (peak 4). (C) On-line HPLC-ABTS ${ }^{+}$chromatogram of chloroform extract of G. lucidum with ABTS radical reagent and the negative peak with respect to peak 4, indicating the antioxidant activity determined at $680 \mathrm{~nm}$.

against DPPH free radicals using the electron spin resonance spectrophotometer (Figure 4). The chloroform fraction showed the highest DPPH radical scavenging activity with an $\mathrm{IC}_{50}$ value of $0.684 \pm 0.31 \mathrm{mg} \mathrm{mL}^{-1}$. The methanol and ethyl acetate fractions showed $\mathrm{IC}_{50}$ values as $1.109 \pm 0.54$ and $2.09 \pm 0.42 \mathrm{mg} \mathrm{mL}^{-1}$, respectively. All fractions increased the DPPH radical scavenging activity (\%) with the increase of concentration, in a dose dependent manner.

\section{Anti-inflammatory activity in terms of NO production inhibitory effect}

Nitric oxide (NO) production by the inflammatory mediators by iNOS, with the different G. lucidum fractions were determined in LPS-activated RAW 264.7 cell in vitro. LPS acts as endotoxins for mammals and stimulates the RAW cells in terms of enhancing the NO concentration in the medium. However, with the 
pretreatment of extracts, decrease of NO production level (\%) was measured at all the concentrations (Figure 5). In this study, methanol and chloroform fractions showed the highest and similar results for inhibitory effect of NO production (\%) on LPS-induced RAW macrophages dose dependently. The calculated $\mathrm{IC}_{50}$ values on $\mathrm{ME}$ and $\mathrm{CE}$ fractions were $33.09 \pm 0.04$ and $30.38 \pm 0.03 \mu \mathrm{g} \mathrm{mL}^{-1}$, respectively (Table 1). The EE fraction showed a lower activity with $\mathrm{IC}_{50}$ values $122.9 \pm 0.82 \mu \mathrm{g} \mathrm{mL}^{-1}$. Therefore, the determined NO production inhibitory activity (\%) was about 4-fold lesser in EE fraction than in ME and CE fractions. In addition, the cytotoxic effects on RAW 264.7 cells with the treated samples were performed by MTT assay. In these tests, G. lucidum fractions did not show a significant cytotoxic effect at all treated concentrations. Therefore, G. lucidum extracts can be considered as potential agents for suppressing NO production without any cytotoxic effect for anti-inflammatory activity.

\section{DISCUSSION}

Sri Lankan basidiomycetes are rich sources of secondary metabolites and preliminary screening bioassays might help to identify possible bioactivities. Nine species of fungi randomly selected from Sri Lankan habitats were tested for antibacterial activity by disc diffusion assay against 2 Gram negative (Escherichia coli and Klebsiella aerogenes) and 2 Gram positive (Bacillus subtilis and Staphylococcus aureus) bacterial strains, respectively. The highest growth inhibition activity was reported in the G. lucidum sample against all the bacterial strains. G. lucidum is a well-known terrestrial fungus and occurs in most of the countries. Some countries including China, Korea and Japan are using G. lucidum extracts or fresh materials directly or indirectly for treatment in traditional medicine (Yue et al., 2010). Recent studies have discussed the pharmacological and medicinal value of G. lucidum. This is the first study on Sri Lankan G. lucidum that has evaluated and reported the bioactivities against antibacterial, antioxidant and anti-inflammatory effects.

In this study, extracted organic solvent fractions were tested using HPLC and the chloroform fraction that had the highest amount of possible secondary metabolites was identified. The on-line HPLC-ABTS ${ }^{+}$chromatogram

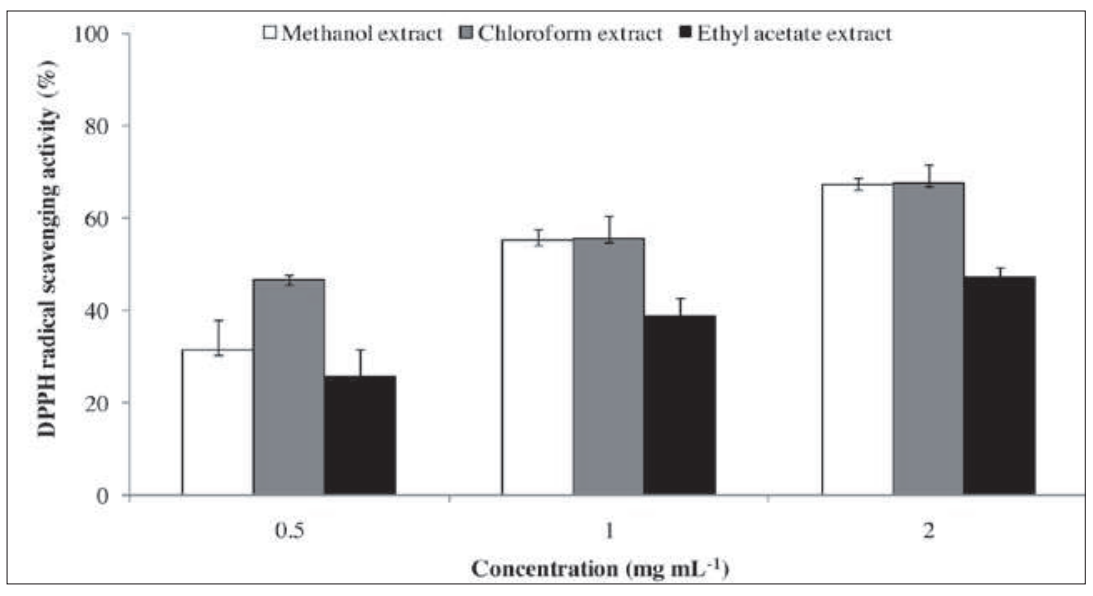

\begin{tabular}{lccc}
\hline & \multicolumn{3}{c}{ Ganoderma lucidum extracts } \\
\hline DPPH Radical scavenging activity (\%) & ME & CE & EE \\
IC $_{50}\left(\mathrm{mg} \mathrm{mL}^{-1}\right)^{\text {a }}$ & $1.109 \pm 0.54$ & $0.684 \pm 0.31$ & $2.09 \pm 0.42$ \\
\hline
\end{tabular}

Figure 4: DPPH radical scavenging activity (\%) of the organic solvent extracts of Ganoderma lucidum determined using electron spin resonance spectrometer (ESR).

a The concentration of the extract required to scavenge $50 \%$ of the antioxidant activity. Values of $\mathrm{IC}_{50}$ were determined by the triplicate individual experiments and values are mean $\pm \mathrm{SD}$ of three determinations.

ME: methanol extract, CE: chloroform extract, EE: ethyl acetate extract. 

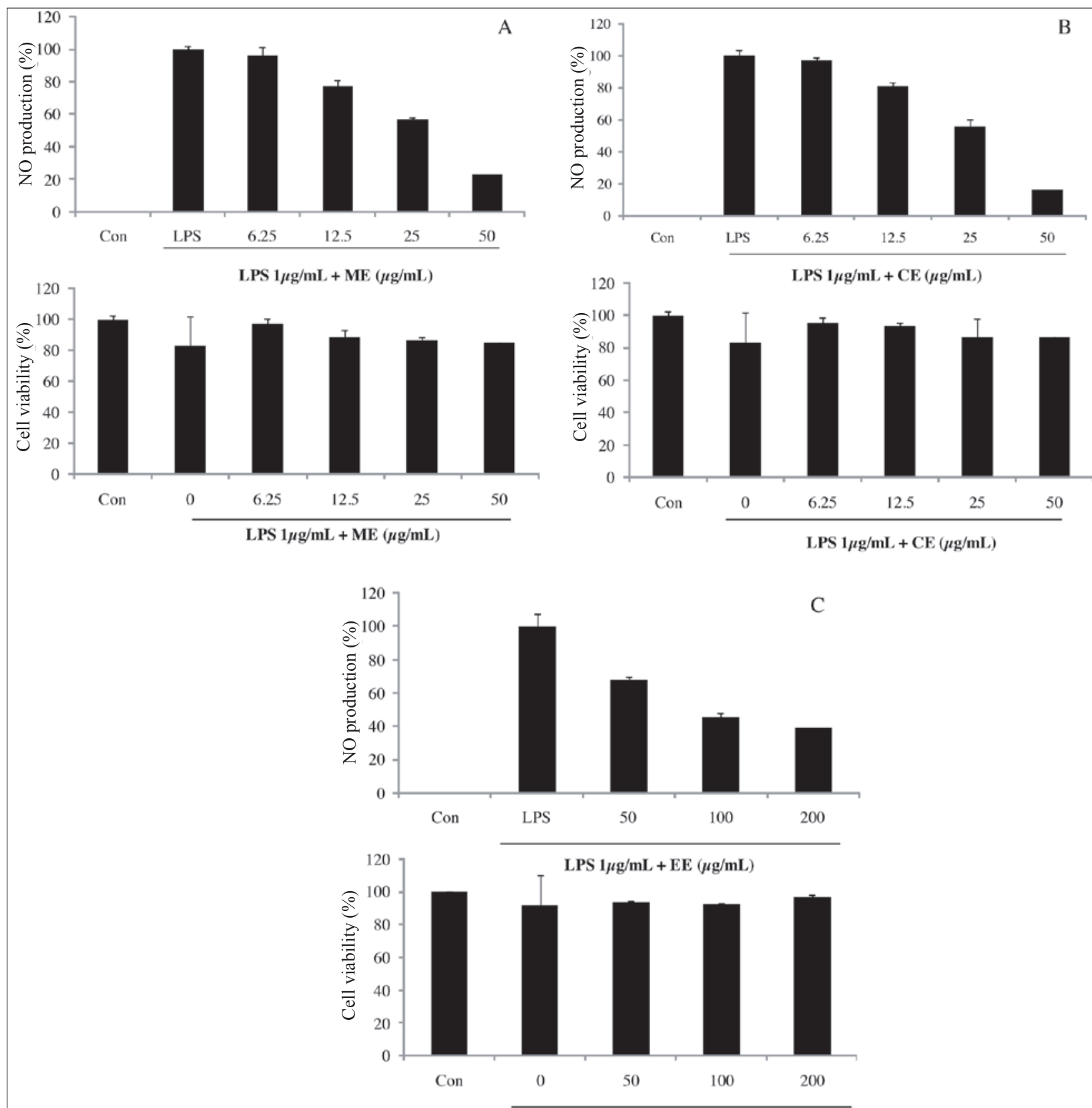

LPS $1 \mu \mathrm{g} / \mathrm{mL}+\mathrm{EE}(\mu \mathrm{g} / \mathrm{mL})$

Figure 5: NO production inhibitory effect of Ganoderma lucidum organic solvent extracts; (A): methanol extract; ME, (B): chloroform extract; CE and (C): ethyl acetate extract; EE on lipopolysaccharide (LPS) induced NO production (\%) and cell viability (\%) in RAW 264.7 macrophages. After incubation of the extract with cells in response to LPS $\left(1 \mu \mathrm{g} \mathrm{mL}^{-1}\right)$ for $24 \mathrm{~h}$, the NO levels in the medium was measured. Values are mean $\pm \mathrm{SD}$ of three determinations.

profile has shown 7 major compounds in the chloroform fraction. Interestingly, the negative peak at $680 \mathrm{~nm}$ of $\mathrm{ABTS}^{+}$profile at $27.0 \mathrm{~min}$ retention time (UV detector at 290 and $365 \mathrm{~nm}$ ) was identified as the antioxidant compound from the chloroform fraction of G. lucidum extract. 
Table 1: Anti-inflammatory activity of Ganoderma lucidum extracts on LPS-induced RAW 264.7 macrophages

\begin{tabular}{lccc}
\hline & \multicolumn{3}{c}{ Ganoderma lucidum extracts } \\
\hline NO production inhibitory activity (\%) & ME & CE & EE \\
$\mathrm{IC}_{50}\left(\mu \mathrm{g} \mathrm{m}^{-1}\right)^{\text {a }}$ & $33.09 \pm 0.04$ & $30.38 \pm 0.03$ & $122.9 \pm 0.82$ \\
\hline
\end{tabular}

${ }^{a}$ The concentration of the extract required to scavenge $50 \%$ of the NO production inhibitory activity (\%). Values of $\mathrm{IC}_{50}$ were determined by the triplicate individual experiments and values are mean $\pm \mathrm{SD}$ of three determinations. ME: methanol extract, CE: chloroform extract, EE: ethyl acetate extract

Following the separation of chloroform extract at $5 \mathrm{mg} \mathrm{mL}^{-1}$ concentration on the HPLC column, the elute was directed to PDA detector and mixed with a stabilized solution of $\mathrm{ABTS}^{+}$radicals. $\mathrm{ABTS}^{+}$radicals are quenching and the results indicate a negative peak on the HPLC trace as illustrated in the $A_{680 \mathrm{~nm}}$ profile (Figure 3 ). The area under the peak depends on the strength of antioxidant activity and is described as an advanced technology to describe natural products quantification through the on-line HPLC-ABTS ${ }^{+}$chromatogram (Stalmach et al., 2006). In addition, DPPH radical scavenging activity (\%) showed that the chloroform fraction has a higher activity $\left(\mathrm{IC}_{50}\right.$ value $\left.0.684 \pm 0.31 \mathrm{mg} \mathrm{mL}^{-1}\right)$ compared to the other organic solvent extracts of $G$. lucidum. In this study, an advanced methodology was used to detect the radical scavenging activity, using electron spin resonance spectrophotometer (ESR). Spin trapping is the most direct method for the detection of highly reactive free radicals, which can overcome the sensitivity problem inherent in the detection of endogenous radicals in biological systems. The prominent antioxidant value achieved from the chloroform fraction complied with the on-line HPLC$\mathrm{ABTS}^{+}$chromatogram.

Inflammation is one of the physiological processes initiated due to the pathogenic invasion or cell and tissue injury (Wadleigh et al., 2000). This can be influenced by the activation of various immune cells such as macrophages, neutrophils and lymphocytes. Nitric oxide (NO) plays an important role in many cellular functions in the biological systems as a signalling molecule (Wang et al., 2006). Importantly, NO is generated in macrophages as a part of the human immune responses (Kassim et al., 2010). Therefore, inflammatory mediators such as nitric oxide (NO) and prostaglandin $\left(\mathrm{PGE}_{2}\right)$ are also activated due to inducible nitric oxide synthase (iNOS) and cyclooxygenase-2 (COX-2). In this study, the pathological condition was stimulated by lipo-polysaccharides (LPS) and the NO production is increased by iNOS. The suppression of iNOS expression and inhibition of NO production by the G. lucidum samples were determined to be of therapeutic potential value of anti-inflammation. The profound inhibitory effect observed in the chloroform extracted fraction $\left(\mathrm{IC}_{50}\right.$ value $\left.33.09 \pm 0.04 \mu \mathrm{g} \mathrm{mL}^{-1}\right)$ and cytotoxic effect against RAW 264.7 macrophages was not seen at all the concentrations. According to the results, the chloroform extract of G. lucidum has profound bioactivities including antibacterial, antioxidant and anti-inflammatory effects. Furthermore, the literature survey has supported the fact that triterpenoid compounds are contained in the chloroform fraction of $G$. lucidum resulting in bioactivities. Yang et al. (2007) have reported that the chloroform fraction of G. lucidum separated a total of 32 triterpenoids, recently. The chloroform fraction of the Sri Lankan G. lucidum has shown profound antibacterial, antioxidant and anti-inflammatory activities, which might have potential to isolate unknown and interesting triterpenoid structures.

\section{REFERENCES}

1. Blackwell M. (2011). The Fungi: 1, 2, 3...5.1 million species? American Journal of Botany 98 (2): 426 - 438.

DOI: http://dx.doi.org/10.3732/ajb.1000298

2. Coomaraswamy U. (1979). A Handbook of the Fungi Parasitic on the Plants of Sri Lanka. National Science Council of Sri Lanka, Colombo 07.

3. De Silva E.D., Van der sar S.A., Santha R.G.L., Wijesundara R.L.C., Cole A.L.J., Blunt J.W. \& Munro M.H.G. (2006). Lanostane triterpenoids from the Sri Lankan Basdiomycete Ganoderma appelantum. Journal of Natural Products 69: 1245 - 1248.

DOI: http://dx.doi.org/10.1021/np0602214

4. Guarro J., Gene J. \& Stchigel A.M. (1999). Developments in fungal taxonomy. Clinical Microbiology Reviews 12: $454-500$.

5. Kassim M., Achoui M., Mustafa M.R., Mohd M.A. \& Yusoff K.M. (2010). Ellagic acid, phenolic acids, and 
flavonoids in Malaysian honey extracts demonstrate in vitro antiinflammatory activity. Nutrition Research 30: $650-659$.

DOI: http://dx.doi.org/10.1016/j.nutres.2010.08.008

6. Lee M.H., Lee J.M., Jun S.H., Lee S.H., Kim N.W., Lee J.H., Ko N.Y., Mun S.H., Kim B.K., Lim B.O., Choi D.K. \& Choi W.S. (2007). The anti-inflammatory effects of Pyrolae herba extract through the inhibition of the expression of inducible nitric oxide synthase (iNOS) and NO production. Journal of Ethnopharmacology 112: 49 54.

DOI: http://dx.doi.org/10.1016/j.jep.2007.01.036

7. Nanjo F., Goto K., Seto R., Suzuki M., Sakai M. \& Hara Y. (1996). Scavenging effects of tea catechins and their derivatives on 1,1-diphenyl-2-picrylydrazyl radical. Free Radical Biology \& Medicine 21: 895 - 902.

DOI: http://dx.doi.org/10.1016/0891-5849(96)00237-7

8. Perera. W.A.S.W., Abeythunga D.T.U. \& Wijesundara R.L.C. (2001). Anti-bacterial activities of Volvariella volvacea. Journal of the National Science Foundation of Sri Lanka 29(1\&2): $61-68$.

9. Petch T. \& Bisby G.R. (1950). The Fungi of Ceylon. Ceylon Government Press, Sri Lanka.

10. Rota C., Carramiñana J.J., Burillo J. \& Herrera A. (2004). In vitro antimicrobial activity of essential oils from aromatic plants against selected food borne pathogens. Journal of Food Protection 67: 1252 - 1256.

11. Stalmach A., Mullen W., Nagai C. \& Crozier A. (2006). On-line HPLC analysis of the antioxidant activity of phenolic compounds in brewed, paper-filtered coffee. Brazilian Journal of Plant Physiology 18(1): 253 - 262.
DOI: http://dx.doi.org/10.1590/S1677-042020060001000 18

12. Wang J.W., Zheng L.P., Wu J.Y. \& Tan R.X. (2006). Involvement of nitric oxide in oxidative burst, phenylalanine ammonia-lyase activation and Taxol production induced by low-energy ultrasound in Taxus yunnanensis cell suspension cultures. Nitric Oxide 15: 351 -358 . DOI: http://dx.doi.org/10.1016/j.niox.2006.04.261

13. Wadleigh D.J., Reddy S.T., Kopp E., Ghosh S. \& Herschman H.R. (2000). Transcriptional activation of the cyclooxygenase-2 gene in endotoxin-treated RAW 264.7 macrophages. The Journal of Biological Chemistry 275: $6259-6266$.

DOI: http://dx.doi.org/10.1074/jbc.275.9.6259

14. Yang M., Wang X., Guan S. \& Xia J. (2007). Analysis of triterpenoids in Ganoderma lucidum using liquid chromatography coupled with electrospray ionization mass spectrometry. American Society for Mass Spectrometry 18: $927-939$. DOI: http://dx.doi.org/10.1016/j.jasms.2007.01.012

15. Yue Q.X., Song X.Y., Ma C., Feng L.X., Guan S.H., Wua W.Y., Yang M., Jiang B.H., Liu X., Cui Y.J. \& Guo D.A. (2010). Effects of triterpenes from Ganoderma lucidum on protein expression profile of HeLa cells. Phytomedicine 17: $606-603$. DOI: http://dx.doi.org/10.1016/j.phymed.2009.12.01

16. Zjawiony J.K. (2004). Biologically active compounds from Aphyllophorales (Polypore) fungi. Journal of Natural Products 67: $300-310$.

DOI: http://dx.doi.org/10.1021/np030372w 